\title{
Database of interconnected fish ponds in De Maten Nature Reserve, Belgium
}

Pieter Lemmens (iD, Karl Cottenie, Frank Van de Meutter, Pieter Vanormelingen \& Luc De Meester
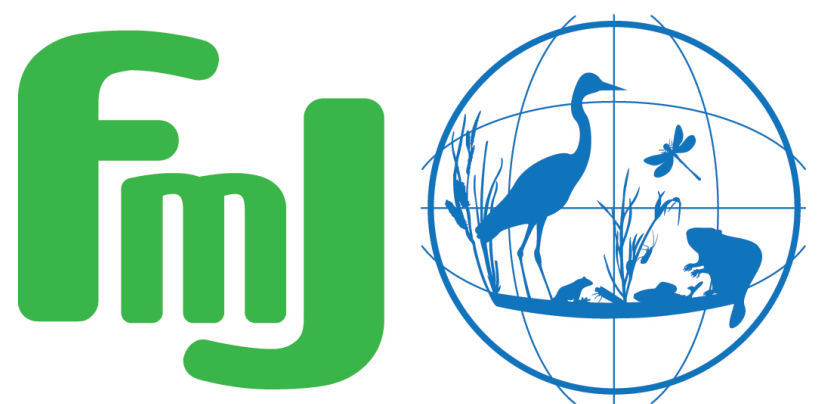

Freshwater Metadata Journal 



\title{
Database of interconnected fish ponds in De Maten Nature Reserve, Belgium
}

\author{
Pieter Lemmens ${ }^{1}$ iD , Karl Cottenie ${ }^{1}$, Frank Van de Meutter ${ }^{1}$, Pieter Vanormelingen ${ }^{2}$ \& \\ Luc De Meester ${ }^{1}$ \\ 1 Laboratory of Aquatic Ecology, Evolution and Conservation, Leuven, Belgium; corresponding author: pieter.lemmens@kuleuven.be \\ 2 Ghent University, Protistology and Aquatic Ecology, Ghent, Belgium
}

Please cite this paper as follows: Lemmens, P., Cottenie, K., Van de Meutter, F., Vanormelingen, P. \& De Meester, L., 2018. Database of interconnected fish ponds in De Maten Nature Reserve, Belgium. Freshwater Metadata Journal 30: 1-8. https://doi.org/10.15504/fmj.2018.30

Received: 2018-09-18 / Published: 2018-09-27

\section{Keywords}

interconnected fish ponds, zooplankton, phytoplankton, macro-invertebrates, environmental conditions

\section{Short description of the dataset/summary}

The De Maten pond dataset contains data on local pond conditions and taxonomic community composition of phytoplankton, zooplankton, macro-invertebrates and fish from 34 interconnected fish ponds in the "De Maten" nature reserve (Limburg, Belgium).

\section{General information}

dataset entry ID:

name of the dataset:

full name of the dataset:

dataset short name:

type of dataset:
SF_11

De Maten fish ponds

De Maten

species (taxonomic group) per site database including environmental information

point data/observation data

data type:

science keywords according to GCMD:

topic:

Biosphere, Biological Classification, Terrestrial Hydrosphere

ISO topic category according to ISO 19115:

INSPIRE keywords according to GEMET:

Biota, Environment, Inland Waters

Habitats and biotopes

own science keywords:

fish ponds, phytoplankton, zooplankton, macro-invertebrates, fish 


\section{Technical and administrative specifications}

$\begin{array}{ll}\text { data format: } & \text { Excel } \\ \text { operating system: } & \text { all Windows systems } \\ \text { data language: } & \text { English } \\ \text { current access level: } & \text { internal } \\ \quad \text { currently available through GBIF: } & \text { no } \\ \text { exchange planned: } & \text { yes } \\ \text { data in data repository: } & \text { no }\end{array}$

Do you plan to publish the data on the Freshwater Biodiversity Data Portal:

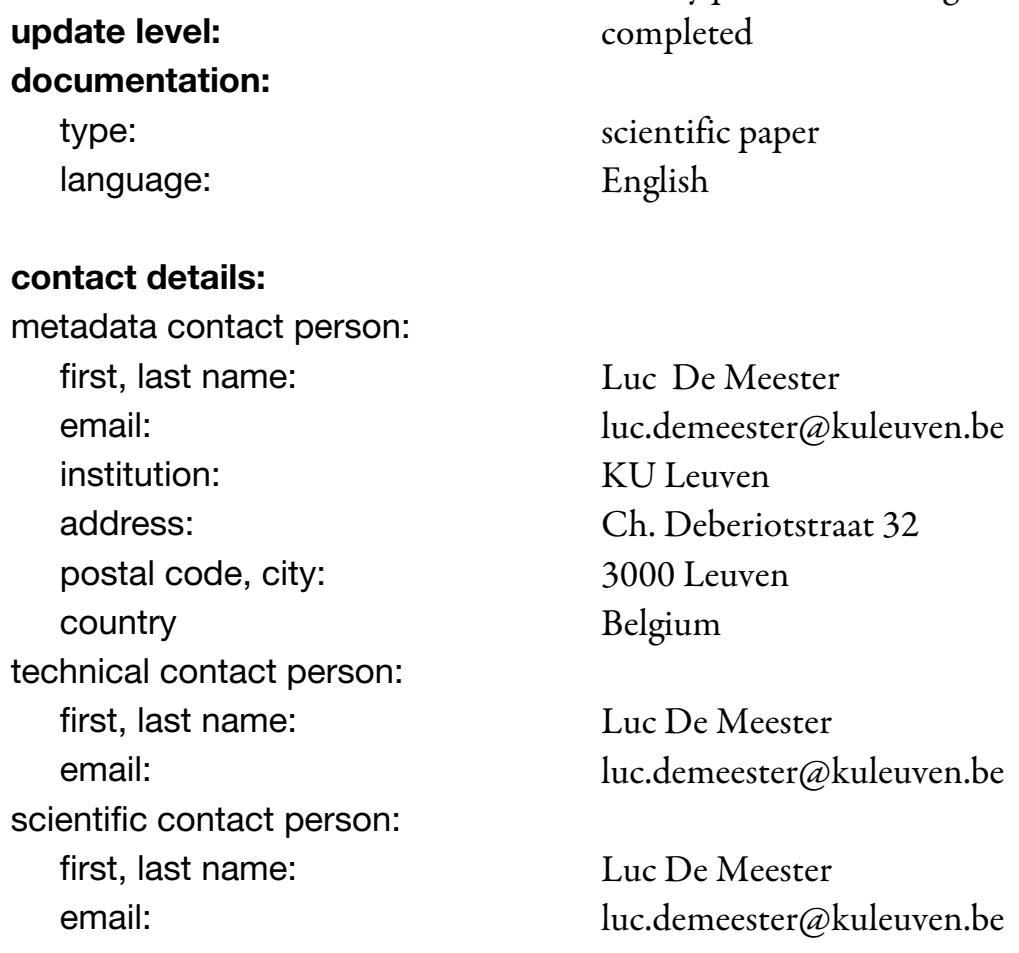
scientific paper English

Luc De Meester

luc.demeester@kuleuven.be

KU Leuven

Ch. Deberiotstraat 32

3000 Leuven

Luc De Meester

luc.demeester@kuleuven.be already published through the Freshwater Biodiversity Data Portal

\section{Intellectual property rights and citation}

dataset creator (data compiler):

contact name:

Pieter Lemmens

contact email:

pieter.lemmens@kuleuven.be

contact institution:

KU Leuven

data contributors to/owners of this dataset:

multiple

number:

5

\section{data contributor/owner 1:}

$\begin{array}{ll}\text { contact name: } & \text { Pieter Lemmens } \\ \text { contact email: } & \text { pieter.lemmens@kuleuven.be } \\ \text { contact institute: } & \text { KU Leuven }\end{array}$

criteria for using this part of the dataset:

The dataset is publicly available (data portal, data archive) and can be used without restrictions, but dataset creator/data contributors must be informed 
data contributor/owner 2:

contact name:

contact email:

contact institute:

criteria for using this part of the dataset:

The dataset is publicly available (data portal, data archive) and can be used without restrictions, but dataset creator/data contributors must be informed prior to publication. Data must be acknowledged and cited correctly.

comments:

\section{data contributor/owner 3:}

contact name:

contact email:

contact institute:

criteria for using this part of the dataset:

Evolution and Conservation at time of data collection.

Frank Van de Meutter

frank.vandemeutter@inbo.be

INBO

The dataset is publicly available (data portal, data archive) and can be used without restrictions, but dataset creator/data contributors must be informed prior to publication. Data must be acknowledged and cited correctly.

comments: This person was working at KU Leuven, Laboratory of Aquatic Ecology, Evolution and Conservation at time of data collection.

data contributor/owner 4:

contact name:

Pieter Vanormelingen

contact email:

pieter.vanormelingen@natuurpunt.be

contact institute:

Natuurpunt

criteria for using this part of the dataset:

The dataset is publicly available (data portal, data archive) and can be used without restrictions, but dataset creator/data contributors must be informed prior to publication. Data must be acknowledged and cited correctly.

comments:

This person was working at Ghent University, Protistology and Aquatic Ecology Evolution and Conservation at time of data collection.

\section{data contributor/owner 5:}

contact name:

Luc De Meester

contact email:

luc.demeester@kuleuven.be

contact institute:

KU Leuven

criteria for using this part of the dataset:

The dataset is publicly available (data portal, data archive) and can be used without restrictions, but dataset creator/data contributors must be informed prior to publication. Data must be acknowledged and cited correctly.

citation of this dataset:

author(s):

Lemmens, P., Cottenie, K., Van de Meutter, F., Vanormelingen, P. \& De

Meester, L.

title and journal (name, number, pages):

Biodiversity in interconnected fish ponds in "De Maten" nature reserve, Belgium

year:

2018

doi:

citation of the metadata:

author(s):

https://doi.org/10.15468/tjbpz7

Lemmens P., Cottenie K., Van de Meutter F., Vanormelingen P. \& De Meester L. 
title and journal (name, number, pages):

Database of interconnected fish ponds in De Maten Nature Reserve, Belgium.

Freshwater Metadata Journal 30: 1-8

year:

2018

doi:

https://doi.org/10.15504/fmj.2018.30

dataset related references:

reference 1:

author(s):

Cottenie, K., Michels, E., Nuytten, N. \& De Meester, L.

title:

Zooplankton metacommunity structure: regional vs. local processes in highly interconnected ponds. Ecology 84: 991-1000.

year:

2003

reference 2:

author(s):

title:

Van de Meutter, F., De Meester, L. \& Stoks, R.

Metacommunity structure of pond macroinvertebrates: effects of dispersal mode and generation time. Ecology 88: 1687-1695.

year:

2007

reference 3:

author(s):

title:

year:

Vanormelingen, P., Cottenie, K., Michels, E., Muylaert, K., Vyverman, W. \& De Meester L.

The relative importance of dispersal and local processes in structuring phytoplankton communities in a set of highly interconnected ponds. Freshwater Biology 53: 2170-2183.

2008

\section{General data specifications}

regional coverage of the dataset:

spatial extent of the dataset: regional

continents:

Europe

spatial extent (bounding coordinates):

southernmost latitude $\left[^{\circ}\right]$ :

49.4969821

northernmost latitude $\left[^{\circ}\right]$ :

51.5516667

westernmost longitude $\left[{ }^{\circ}\right]$ :

2.3889137

easternmost longitude $\left[{ }^{\circ}\right]$ :

6.408097

countries:

Europe: Belgium

world climatic regions according to Köppen:

Group D: continental/microthermal climate

freshwater ecoregions of the world (FEOW) according to WWF:

Europe: Central \& Western Europe

European ecoregions according to Illies (WFD):

Western Plains (ER13)

ecosystem type:

lakes/ponds

covered timeframe:

$1996-2003$

\section{Site specifications}

coordinate system/grid data:

datum (e.g. WGS84): latitude/longitude, format: DD

projected, UTM

WGS84 
grid data available:

no

ecosystem type classification:

lakes (classification mainly according to WFD):

depth typology based on mean depth

$<3 \mathrm{~m}$

site coding:

site coding available: yes, numerical

number of digits: 2

example: $\quad 10$

number of sites: $\quad<100$

exact number of sites: $\quad 34$

\section{Climate and environmental data}

climate related data:

environmental data:

available parameters per site:

comments:

physico-chemical data:

availability of physico-chemical data, if there is more than one sample per site:

stressors influencing the sites:

\section{Biological data}

biological data origin:

organism group addressed: mean values per site

no climate data available

no environmental data per catchment available

information on riparian vegetation (incl. information on modification)

data source: visual inspection

mean depth

data source: as determined during sampling

Additionally: coverage with submerged aquatic vegeation.

total $\mathrm{P}$, total $\mathrm{N}$, oxygen content, $\mathrm{pH}$, conductivity, chlorophyll, Secci disc depth no stressor data available

\section{Sample specifications/sample resolution}

\section{fish:}

\section{sample information:}

covered timeframe:

from sampling,

PhD research

historical data:

$1996-2002$

palaeo data:

no

season:

no

summer

temporal resolution/frequency of sampling:

time series data:

per year

no 


\section{taxonomic resolution:}

level: $\quad$ species

percentage of species level data: 100

\section{taxonomic coding:}

taxalist according to:

reference(s):

\section{FishBase}

Froese, R. \& Pauly, D. Editors. 2018. FishBase. World Wide Web electronic publication. www.fishbase.org, version (06/2018).

\section{sample specifications:}

type:

quantitative (abundance data)

replicate samples:

no

specification of method(s) used for sampling and sorting:

For details see Cottenie et al. (2003) and Van de Meutter et al. (2007).

reference(s):

Cottenie, K., Michels, E., Nuytten, N. \& De Meester, L., 2003. Zooplankton metacommunity structure: regional vs. local processes in highly interconnected ponds. Ecology 84: 991-1000.

Van de Meutter F., De Meester, L. \& Stoks, R., 2007. Metacommunity structure of pond macroinvertebrates: effects of dispersal mode and generation time. Ecology 88: 1687-1695.

\section{macro-invertebrates:}

\section{sample information:}

covered timeframe:

$2001-2003$

historical data:

no

palaeo data:

no

season:

spring, summer, autumn

temporal resolution/frequency of sampling:

time series data:

per year

no

\section{taxonomic resolution:}

level:

family, species

percentage of species level data: 90

\section{taxonomic coding:}

taxalist according to:

De Pauw, N. \& Vannevel, R. (1991)

reference(s):

De Pauw, N. \& Vannevel, R., 1991. Macro-invertebraten en waterkwaliteit.

Antwerpen: Stichting Leefmilieu.

sample specifications:

type:

replicate samples:

quantitative (abundance data)

no

specification of method(s) used for sampling and sorting:

For details see Van de Meutter et al. (2007).

reference(s):

Van de Meutter, F., De Meester, L. \& Stoks, R., 2007. Metacommunity structure of pond macroinvertebrates: effects of dispersal mode and generation time. Ecology 88: 1687-1695.

\section{zooplankton:}

sample information:

$\begin{array}{ll}\text { covered timeframe: } & 1996-1998 \\ \text { historical data: } & \text { no } \\ \text { palaeo data: } & \text { no } \\ \text { season: } & \text { summer }\end{array}$

temporal resolution/frequency of sampling: 
time series data:

taxonomic resolution:

level:

percentage of species level data: 100

taxonomic coding:

taxalist according to:

reference(s):

sample specifications:

type:

replicate samples:

specification of method(s) used for sampling and sorting:

For details see Cottenie et al. (2003).

reference(s):

\section{phytoplankton:}

sample information:

covered timeframe:

historical data:

season:

$1998-1998$

no

summer

temporal resolution/frequency of sampling:

per year

time series data:

no

taxonomic resolution:

level:

\section{taxonomic coding:}

taxalist according to:

reference(s):

\section{sample specifications:}

type:

replicate samples:

specification of method(s) used for sampling and sorting:

reference(s)
For details see Vanormelingen et al. (2008).

genus

John et al. (2002)

John, D.M., Whitton, B.A. \& Brook, A.J., 2002. The freshwater algal flora of the British isles. Cambridge: Cambridge University Press.

quantitative (abundance data)

no

Vanormelingen, P., Cottenie, K., Michels, E., Muylaert, K., Vyverman, W. \& De Meester, L., 2008. The relative importance of dispersal and local processes in structuring phytoplankton communities in a set of highly interconnected ponds. Freshwater Biology 53: 2170-2183.

\section{Other specifications}

GIS layers, shape files related to the dataset:

$\begin{array}{ll}\text { availability of photos: } & \text { no data available } \\ \text { availability of maps: } & \text { no } \\ \text { quality control procedures: } & \text { no }\end{array}$

Were any quality control procedures applied to your dataset? 
quality control protocols and comments:

Species names were checked using the GBIF species list. In addition, the quality of data has been checked with the phwhip validator.

\section{Acknowledgements}

The authors acknowledge the National Fund of Scientific Research Flanders for funding (grant G.0358.01) the original sampling and research, and thank the Belgian Science Policy (Belspo) for funding the SAFRED project (Saving freshwater biodiversity research data) that allowed processing and publishing this data.

\section{References}

Cottenie, K., Michels, E., Nuytten, N. \& De Meester, L., 2003. Zooplankton metacommunity structure: regional vs. local processes in highly interconnected ponds. Ecology 84: 991-1000.

https://doi.org/10.1890/0012-9658(2003)084[0991:ZMSRVL]2.0.CO;2

Van de Meutter, F., De Meester, L. \& Stoks, R., 2007. Metacommunity structure of pond macroinvertebrates: effects of dispersal mode and generation time. Ecology 88: 1687-1695. https://doi.org/10.1890/06-0333.1

Vanormelingen, P., Cottenie, K., Michels, E., Muylaert, K., Vyverman, W. \& De Meester, L., 2008. The relative importance of dispersal and local processes in structuring phytoplankton communities in a set of highly interconnected ponds. Freshwater Biology 53: 2170-2183. https://doi.org/10.1111/j.1365-2427.2008.02040.x 